\title{
SISTEM INFORMASI AKUNTANSI PENGELOLAAN DATA PERGULIRAN PINJAMAN DI UNIT PELAKSANA KEGIATAN (UPK) PNPM MANDIRI PERDESAAN
}

\author{
Nur Hudha Wijaya' ${ }^{1)}$, Hanifah Rahmi Fajrin'1), Desi Susilawati ${ }^{2}$ \\ 1) Program Vokasi, Prodi Teknik Elektromedik, Universitas Muhammadiyah Yogyakarta \\ ${ }^{2)}$ Program Vokasi, Akuntansi Terapan, Universitas Muhammadiyah Yogyakarta \\ nurhudhawijaya@umy.ac.id
}

DOI : 10.31604/jpm.v2i1.26-35

\begin{abstract}
Accounting information system (SIA) currently in use by different types of institutions to manage data and information related to the accounting system on a business that is run by the institution. The goal to be achieved is to simplify the process of analysis of the financial control systems for accounting, business strategy, and financial reporting. This devotion took the case study data management revolving loan at a financial institution which is engaged in the provision of entrepreneurial capital loans to the community. Methods undertaken, i.e., analyze documents, interviews to managers of organizations and new business processes, observations continued making the application SIA. The result is the application SIA of information technology service in the field of accounting with the client-server model for the resource efficiency of the organization. With the use of a test application to financial controller system of revolving loan is helpful for financial management in Implementing activities (UPK) Sub Dlingo, with proven fluency revolving loan and financial system well-coordinated.
\end{abstract}

Keywords: SIA, Applications, Finance, Accounting.

\begin{abstract}
Abstrak
Sistem informasi akuntansi (SIA) saat ini digunakan oleh berbagai jenis lembaga untuk mengelola data dan informasi yang terkait dengan sistem akuntansi pada bisnis yang dijalankan oleh lembaga tersebut. Tujuan yang ingin dicapai adalah memudahkan proses analisis akuntansi untuk sistem pengendalian keuangan, strategi bisnis dan penerbitan pelaporan keuangan. Pengabdian ini mengambil studi kasus pengelolaan data perguliran pinjaman pada lembaga keuangan yang bergerak dalam penyediaan pinjaman modal wirausaha kepada masyarakat. Metode yang dilaksanakan yaitu melakukan analisis dokumen, wawancara kepada pengelola organisasi dan pengamatan proses bisnis, baru dilanjutkan pembuatan aplikasi SIA. Hasil pengabdian merupakan penerapan teknologi informasi dalam bidang akuntansi dengan model client-server untuk efisiensi sumberdaya organisasi. Dengan uji penggunaan aplikasi SIA untuk sistem pengendali keuangan pinjaman bergulir sangat membantu untuk pengelolaan keuangan di Unit Pelaksana Kegiatan (UPK) Kecamatan Dlingo, dengan dibuktikan kelancaran sistem keuangan pinjaman bergulir dan terkoordinasi dengan baik.
\end{abstract}

Kata kunci: SIA, Aplikasi, Keuangan, Akuntansi.

MARTABE : Jurnal Pengabdian Masyarakat $\mid 26$ 


\section{PENDAHULUAN}

Pada saat PNPM Mandiri Perdesaan masih berlangsung, setiap program pemberdayaan ekonomi pada setiap kecamatan dilaksanakan oleh Unit Pengelola Kegiatan (UPK). Setelah PNPM Mandiri Perdesaan dihentikan oleh pemerintah pada tahun 2014, kegiatan pemberdayaan yang masih terus dilanjutkan yaitu pengelolaan dana pinjaman kolektif untuk menyelamatkan modal yang masih beredar di masyarakat. Di seluruh Indonesia, dana bergulir yang beredar dimasyarakat ketika PNPM Mandiri dihentikan pada akhir tahun 2014 total senilai kurang lebih 12,7 triliun rupiah (Jafar 2016). Mulai saat itu pula pengelola tidak lagi menggunakan istilah PNPM Mandiri secara formal, namun hanya menggunakan istilah Unit Pengelola Kegiatan (UPK) saja. Bahkan logo kelembagaan sudah banyak yang diubah sesuai semangat pemberdayaan masyarakat masing-masing wilayah kecamatan. Namun bentuk organisasi UPK PNPM mandiri Perdesaan masih mempertahankan struktur yang sesuai dengan PTO, seperti pada gambar 1.

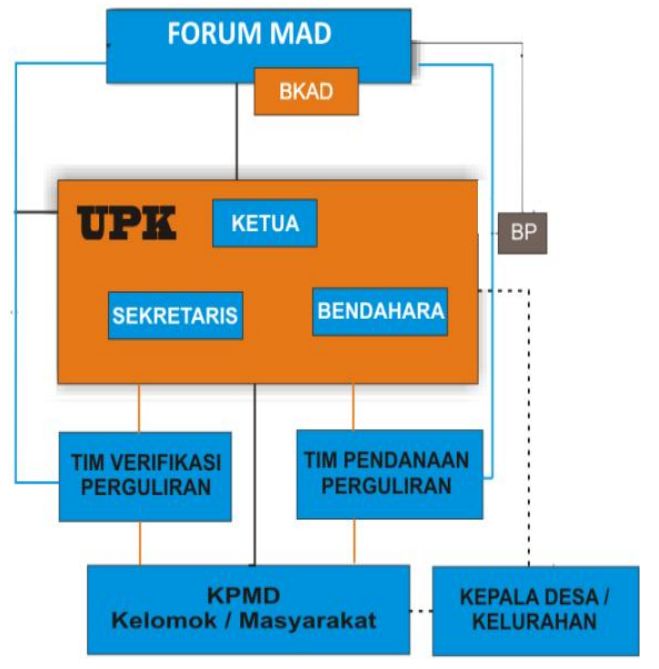

Gambar 1: Struktur Organisasi UPK setelah tahun 2014
Hampir semua UPK melanjutkan kegiatan perguliran dana pinjaman dengan mengacu pada pola dan peraturan yang berlaku ketika PNPM Mandiri masih berlangsung untuk mencegah timbulnya gejolak di masyarakat (pnpm-mandiri.org 2011). Pola pinjaman kolektif yang dijalankan ada dua skema, yaitu Simpan Pinjam Perempuan (SPP) untuk kelompok UKM perempuan dan Usaha Ekonomi Produktif untuk kelompok umum.

Akibat lain yang timbul dari dihentikannya PNPM Mandiri adalah meningkatnya pinjaman bermasalah sebagai dampak dari hilangnya tanggung jawab tanggung renteng dalam wujud pengurangan alokasi dan pengalihan jatah hibah pembangunan fisik pada desa yang terdapat pinjaman bermasalah. Oleh karena itu ada UPK yang berusaha mentransformasikan proses bisnisnya menjadi lembaga keuangan mikro (LKM) dan koperasi agar memiliki kekuatan hukum yang pasti terhadap upaya pengembalian pinjaman bermasalah tersebut (Isfahani 2015). Menurut laporan yang dirilis pada pertemuan forum UPK tingkat nasional pada bulan April tahun 2016 di Yogyakarta, terdapat 4 UPK di Indonesia yang proses bisnisnya bertransformasi menjadi lembaga keuangan mikro maupun koperasi (Anonim 2016).

Pada masa PNPM Mandiri berlangsung, pelaksanaan program setiap unit kerja termasuk di seluruh kecamatan di Kabupaten Bantul menggunakan sistem padat karya dengan tujuan menyerap tenaga kerja di bidang pemberdayaan masyarakat setelah masa tanggap darurat bencana gempa bumi tahun 2006 (Saktiyana 2010). Pada masa itu belum disiapkan perangkat teknologi yang dapat digunakan untuk mengelola pemberdayaan masyarakat. Setelah 
PNPM Mandiri dihentikan, tenaga fasilitator lapangan yang membantu teknis pengelolaan dana pinjaman bergulir sebagian besar ditempatkan sebagai pendamping Desa, yang salah satu tugasnya adalah memfasilitasi pembangunan Desa berbasis partisipatif seperti halnya tugas pada masa PNPM Mandiri (Kementerian Desa 2015).

Persoalan masa kini yang dihadapi oleh UPK secara umum temasuk di Kabupaten Bantul adalah pengelolaan dana pinjaman bergulir, menyangkut persoalan administrasi pinjaman dan laporan keuangan, persoalan penanganan pinjaman bermasalah di tingkat pemanfaat (anggota kelompok) dan masalah pendampingan usaha mikro agar peminjam memiliki kemampuan mengembalikan pinjaman (Kurniawanto 2014). Keterbatasan jumlah pengelola menyebabkan persoalan di lapangan sulit dijangkau dan diselesaikan.

Secara empiris bahwa dengan dihentikannya PNPM Mandiri maka satu-satunya pendapatan yang diperoleh untuk melanjutkan kegiatan pemberdayaan masyarakat adalah jasa atau bunga. Usaha meraih pendapatan terdapat berbagai masalah, dari aspek administrasi hingga manajemen keuangan (Irastina 2013). Dari hasil wawancara pada survey awal, pengelola menyampaikan perlunya penerapan teknologi tepat guna untuk membantu persoalan administrasi dan manajemen keuangan.

Masalah yang ada di pengelolaan data perguliran yaitu rekapitulasi catatan transaksi keuangan yang disusun dalam wujud laporan keuangan, antara lain: neraca, laporan rugi laba, laporan laporan perkembangan pinjaman, laporan kolektibilitas pinjaman, laporan nilai aktiva tetap, laporan hasil analisis perkembangan pinjaman dan pengelolaan keuangan. Pada aspek pengawasan dan pembinaan kelompok peminjam terdapat masalah antara lain: mengantisipasi anggota kelompok peminjam yang tercatat sebagai anggota di kelompok lain sehingga berpotensi mengakibatkan pinjaman ganda pada satu orang, penjadwalan ulang pinjaman bermasalah untuk menekan indeks kolektibiltas pinjaman dan potensi kelompok yang terindikasi tidak lancar melakukan pengembalian pinjaman. Keseluruhan laporan tersebut menjadi bahan strategi perguliran dan laporan pertanggungjawaban Ketua UPK pada forum musyawarah antar desa (MAD).

\section{METODE PELAKSANAAN}

Pelaksanaan dengan mengambil data menggunakan teknik wawancara, investigasi dokumen dan pengamatan proses bisnis, kustomisasi aplikasi akuntansi, instalasi aplikasi dan migrasi data serta pelatihan user dan pendampingan penggunaan aplikasi di lokasi penelitian seperti pada Gambar 2. Hasil yang diharapkan adalah tingkat kesesuaian prosedur bisnis aplikasi terhadap PTO dan tingkat kepuasan user terhadap sistem navigasi pada hasil kustomisasi prototipe aplikasi akuntansi. Proses pencatatan keuangan pada perguliran pinjaman mengacu pada sistem akuntansi yang dipelajari melalui studi pustaka, sedangkan kustomisasi aplikasi mengacu pada kerangka kerja Zachman (Zachman Framework) agar penerapan teknologi informasi sesuai dengan arsitektur bisnis UPK PNPM Mandiri Perdesaan. 


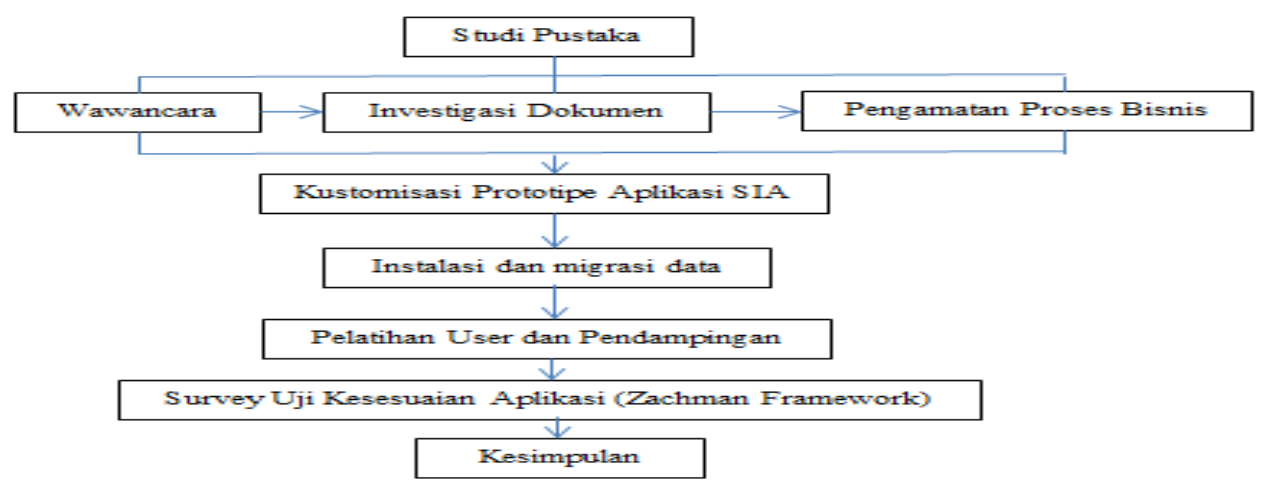

Gambar 2: Tahapan Penelitian

\begin{abstract}
Investigasi
Investigasi dilakukan dengan

cara wawancara langsung dengan pengurus UPK melakukan analisis
\end{abstract}

dokumen, wawancara kepada pengelola organisasi dan pengamatan proses bisnis, baru dilanjutkan pembuatan aplikasi SIA

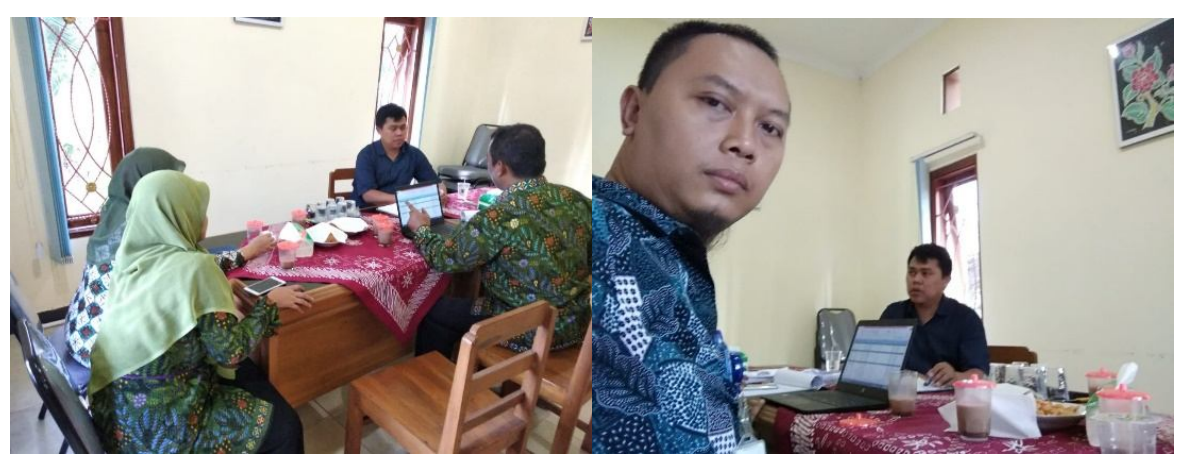

Gambar 3: Wawancara

\section{Kustomisasi}

Kustomisasi merupakan proses perubahan kode program untuk menyesuaikan kode program aplikasi akuntansi yang sebelumnya sudah ada. Kode program aplikasi ini telah dipakai pada UPK PNPM Perdesaan di wilayah lain dengan beberapa perbedaan prosedur bisnis seperti pada gambar 4 .

Migrasi data adalah proses memindahkan data dari format manual ke sistem aplikasi basis data. Pada penelitian ini aplikasi basis data yang digunakan adalah MySQL Server versi 5.11. Proses migrasi dirancang melalui tahap konsolidasi data, yaitu mengumpulkan catatan transaksi manual yang saling terkait dan diisikan pada format file khusus yang dirancang sesuai aplikasi migrasi data eksternal. Aplikasi eksternal yang dimaksud adalah aplikasi khusus untuk memvalidasi data hasil konsolidasi dan menjalankan proses pemindahan data transaksi ke tabel-tabel pada sistem basis data relasional. 


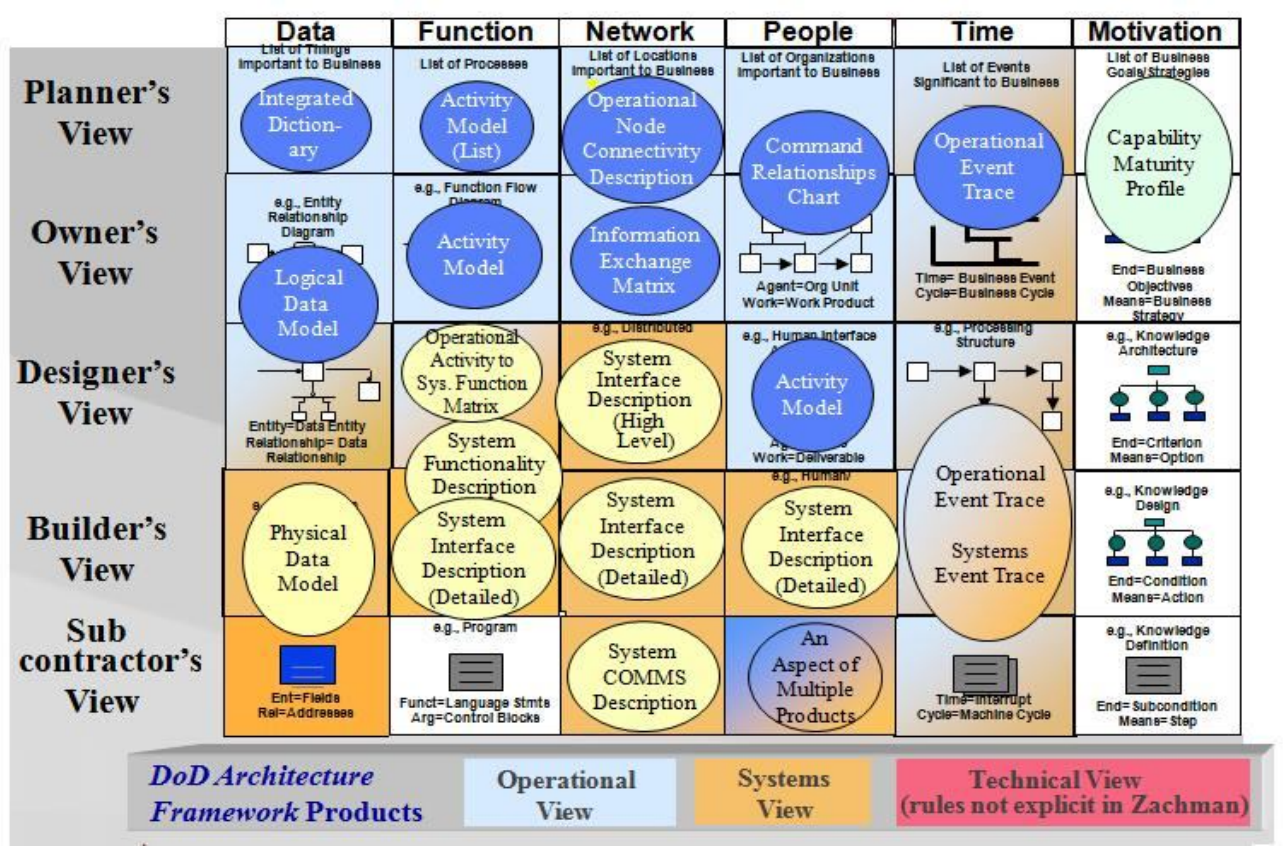

Gambar 4: Zachman Framework

\section{Instalasi}

Proses installing software pada personal computer sehingga software yang akan diterapkan dapat berjalan sesuai yang di rencanakan, aplikasi yang terinstal seperti yang ditunjukkan pada gambar 5 .

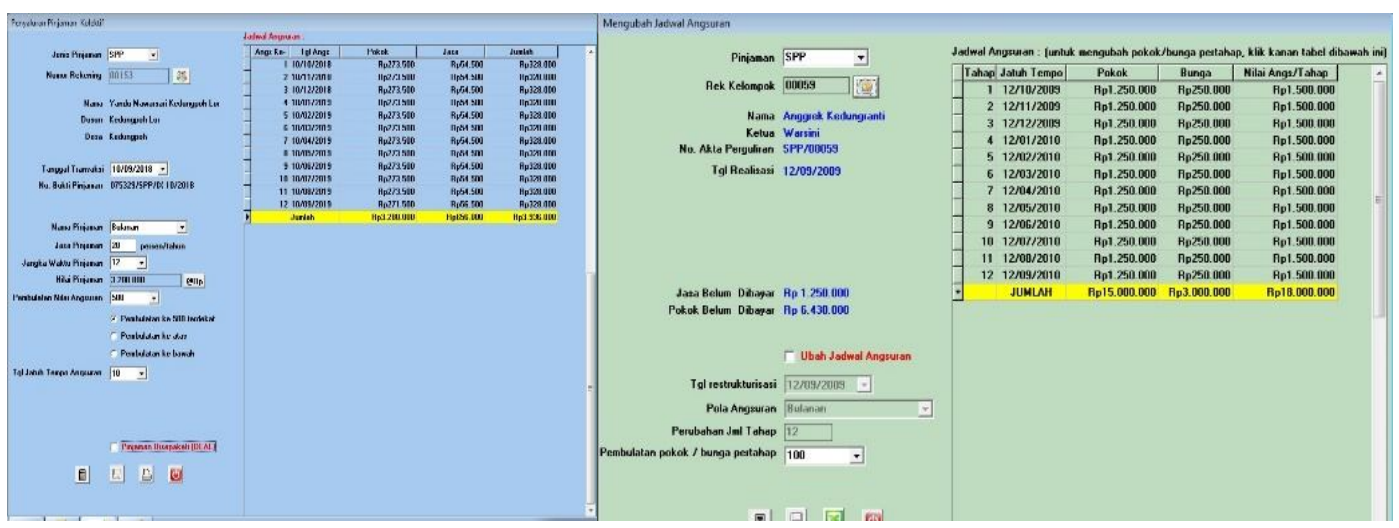

Gambar 5: Proses Instalasi software SIA

\section{Pelatihan}

Pelatihan penggunaan aplikasi SIA dilakukan kepada Unit Pengelola Keuangan (UPK) di kecamatan Dlingo agar familiar dengan tools yang tersedia pada software SIA seperti yang ditunjukkan pada gambar 6. Pelatihan dan pendampingan penggunaan aplikasi merupakan proses transfer knowledge tentang tatalaksana aplikasi, pemeliharaan data dan revisi aplikasi jika pada proses tersebut masih ditemukan adanya bug pada kustomisasi aplikasi yang telah dilakukan sebelumnya. 

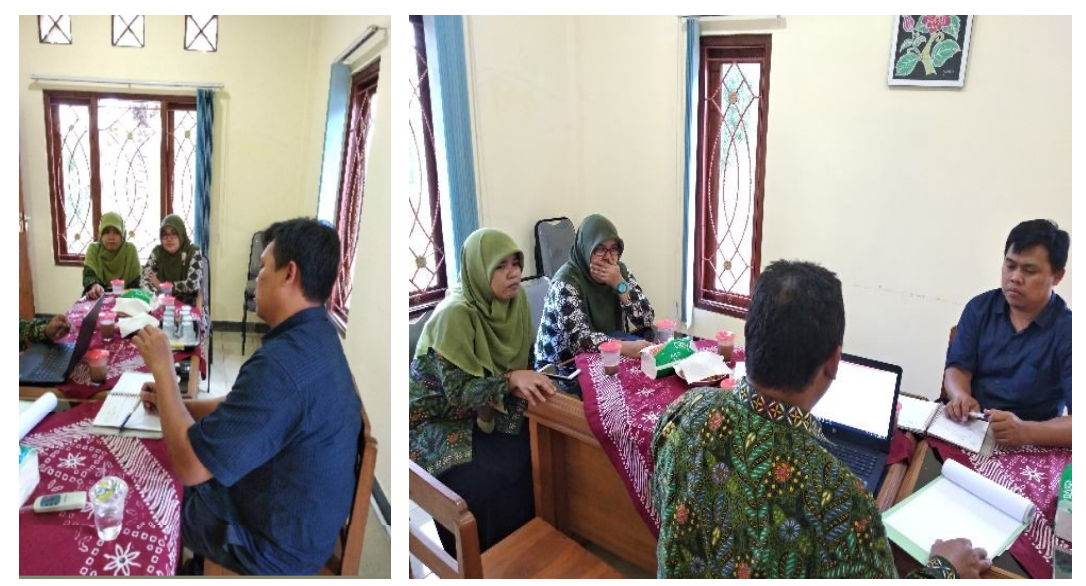

Gambar 6: Pelatihan penggunaan sistem aplikasi SIA

\section{Evaluasi/kesimpulan}

Evaluasi yang dimaksut adalah melihat sistem kerja dari software yang sudah di install dan sejauh mana team UPK dapat memanfaatkannya dengan baik sesuai dengan yang direncanakan.

\section{HASIL DAN PEMBAHASAN}

Penerapan teknologi informasi pada pengelolaan data perguliran pinjaman UPK PNPM Mandiri ini merupakan proses pengembangan sistem informasi akuntansi. Penerapan teknologi ini tidak mengubah proses bisnis secara fundamental, tetapi mengubah prosedur penggunaan catatan keuangan dari sistem manual ke sistem elektronik sehingga akan berdampak pada kebutuhan perubahan kemampuan sumberdaya organisasi UPK PNPM Mandiri. Proses pencatatan data secara manual yang selama ini dirasakan tidak praktis dan tidak mudah ditelusuri dan dikategorisasi akan berubah menjadi proses yang wujudnya secara fisik adalah file-file data yang saling terhubung dan menggunakan kode pencatatan yang berbeda dengan proses manual.

Atas dasar perubahan metode pengelolaan data transaksi tersebut, maka untuk menjamin adanya kesamaan fungsi data dan informasi yang dihasilkan diperlukan transformasi nilai fungsi menggunakan kerangka kerja Zachman seperti pada Gambar 4. Pada penelitian ini kerangka kerja Zachman dipilih sebagai instrumen fungsional karena dapat mencakup fungsi data dan informasi dari tataran konseptual hingga tataran praktis. Dengan kata lain, penerapan teknologi informasi yang dilakukan pada proses pengelolaan data dan informasi perguliran pinjaman nilai fungsinya pada setiap perspektif harus bersifat konstan atau mengalami perluasan. 
Tabel 1: Data function

\begin{tabular}{|c|c|c|c|c|c|c|}
\hline & $\mathbf{D A}^{\prime}$ & $\mathbf{N}$ & NETWORK & PEOPLE & TIME & MOTIVATION \\
\hline $\begin{array}{c}\text { Planner's } \\
\text { View }\end{array}$ & $\begin{array}{r}\text { Pencatatan } \\
\text { dalam si } \\
\text { sistem }\end{array}$ & \begin{tabular}{|c|} 
Data dan \\
informasi dilihat \\
sebagai siklus
\end{tabular} & $\begin{array}{c}\text { Data dan informasi } \\
\text { dapat diakses } \\
\text { melalui jaringan }\end{array}$ & $\begin{array}{c}\text { Sesuai dengan } \\
\text { struktur } \\
\text { organisasi }\end{array}$ & $\begin{array}{r}\text { Prc } \\
\text { kom } 1 \\
\text { sesuai } \\
\text { proses }\end{array}$ & $\begin{array}{r}\text { Mem } \\
\text { mendu } \\
\text { yaitu p } \\
\text { ma }\end{array}$ \\
\hline $\begin{array}{l}\text { Owner's } \\
\text { View }\end{array}$ & \multirow{2}{*}{$\begin{array}{l}\text { Pemodelan data } \\
\text { sesuai dengan } \\
\text { standar } \\
\text { pencatatan } \\
\text { akuntansi }\end{array}$} & $\begin{array}{r}\text { Mode } \\
\text { digunak } \\
\text { dengan } \\
\text { opera }\end{array}$ & $\begin{array}{l}\text { Mamp } \\
\text { inform } \\
\text { yang }\end{array}$ & \begin{tabular}{|} 
pesain interface \\
memudahkan \\
pengoperasian \\
aplikasi \\
\end{tabular} & \multirow{2}{*}{$\begin{array}{c}\text { Proses } \\
\text { pencarian data } \\
\text { dapat dilakukan } \\
\text { dengan cepat }\end{array}$} & $\begin{array}{r}\text { Arsitektur } \\
\text { informasi } \\
\text { dengan ken } \\
\text { organi }\end{array}$ \\
\hline $\begin{array}{l}\text { esigner's } \\
\text { View }\end{array}$ & & $\begin{array}{r}\text { Rincian } \\
\text { aplikas } \\
\text { kebutul }\end{array}$ & $\begin{array}{c}\text { Aplikasi memiliki } \\
\text { kompatibilitas } \\
\text { dengan protokol } \\
\text { TCP }\end{array}$ & \begin{tabular}{|c|} 
Mampu \\
menyajikan \\
informasi yang \\
detil
\end{tabular} & & $\begin{array}{c}\text { Desain sistem } \\
\text { informasi mampu } \\
\text { mengakomodasi } \\
\text { kebutuhan informasi }\end{array}$ \\
\hline $\begin{array}{c}\text { Builder's } \\
\text { View }\end{array}$ & $\begin{array}{r}\text { Sifat fi } \\
\text { mudi } \\
\text { men }\end{array}$ & $\begin{array}{r}\text { Sistem } \\
\text { sesu }\end{array}$ & $\begin{array}{r}\text { Pelapc } \\
\text { diak } \\
\text { jal }\end{array}$ & pek & Efisiensi waktu & $\begin{array}{l}\text { Efisiens } \\
\text { berhas }\end{array}$ \\
\hline $\begin{array}{c}\text { Sub } \\
\text { ontractor' } \\
\text { s View }\end{array}$ & $\begin{array}{l}\text { Pengalamatan } \\
\text { data sesuai } \\
\text { kaidah sistem } \\
\text { akuntansi }\end{array}$ & $\begin{array}{l}\text { Pelapo } \\
\text { di-cro }\end{array}$ & \multicolumn{2}{|c|}{$\begin{array}{l}\text { Mendukung user mengerjakan } \\
\text { tugas secara bersamaan }\end{array}$} & \begin{tabular}{|c|} 
Memberi \\
dukungan pada \\
proses \\
multitasking
\end{tabular} & $\begin{array}{l}\text { Data keuangan } \\
\text { terdokumentasi } \\
\text { dengan baik }\end{array}$ \\
\hline & \multicolumn{2}{|c|}{ Desain konseptual } & sist uperasional & Aspek sistem & \multicolumn{2}{|c|}{ Sisi teknis dan dukungan } \\
\hline
\end{tabular}

Penerima pinjaman pada UPK PNPM Mandiri bersifa kolektif dan tanggung renteng, artinya pinjaman hanya dapat diberikan secara kolektif dan ada pertanggungjawaban secara kolegial antar anggota. Kelompok peminjam harus didaftarkan dahulu sebelum dapat memanfaatkan dana pinjaman. Proses registrasi ini digunakan untuk mengidentifikasi kebutuhan dana pinjaman dan bentuk bisnis yang akan didanai menggunakan pinjaman tersebut. Setiap kelompok peminjam harus memiliki bentuk kepengurusan minimal ketua, bendahara dan sekretaris. Setiap anggota wajib memiliki usaha mikro atau usaha rumah tangga karena sifat pinjaman adalah pemberdayaan ekonomi dan tidak diijinkan apabila dana pinjaman digunakan untuk keperluan konsumtif. Proses registrasi kelompok peminjam dapat dilihat pada gambar 7 .

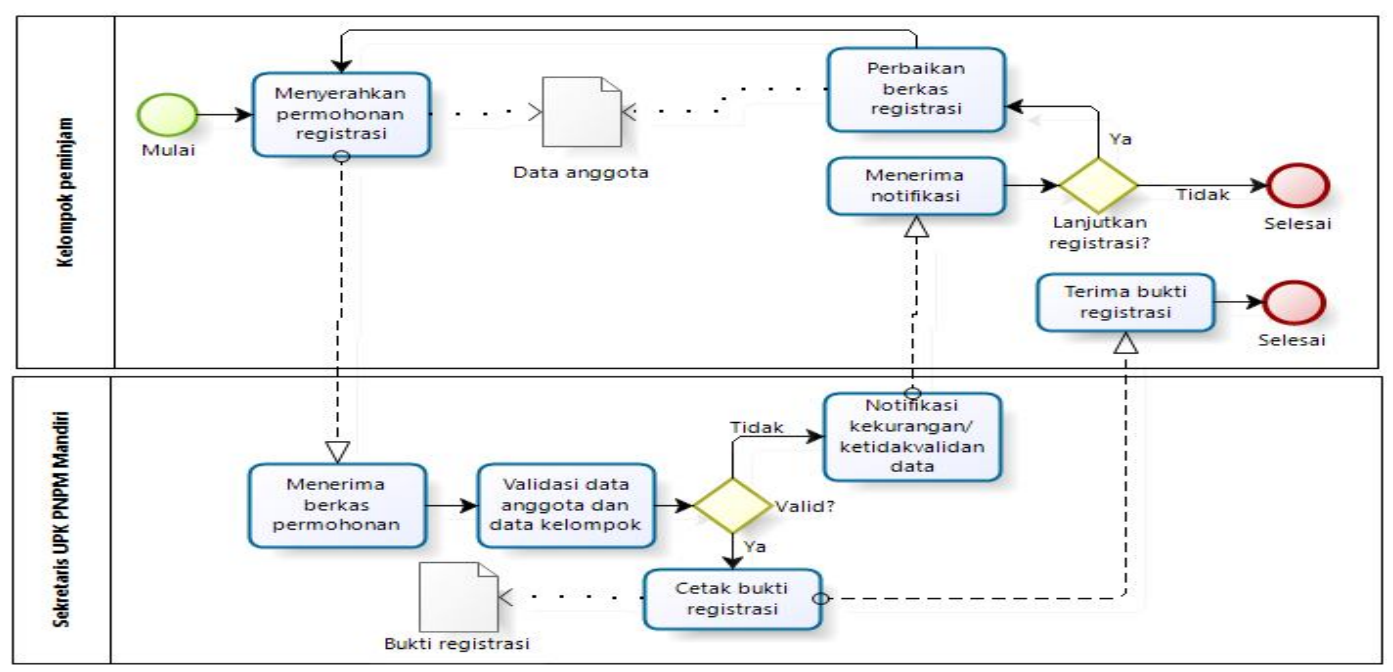

Gambar 7: Diagram proses registrasi peminjam kolektif 


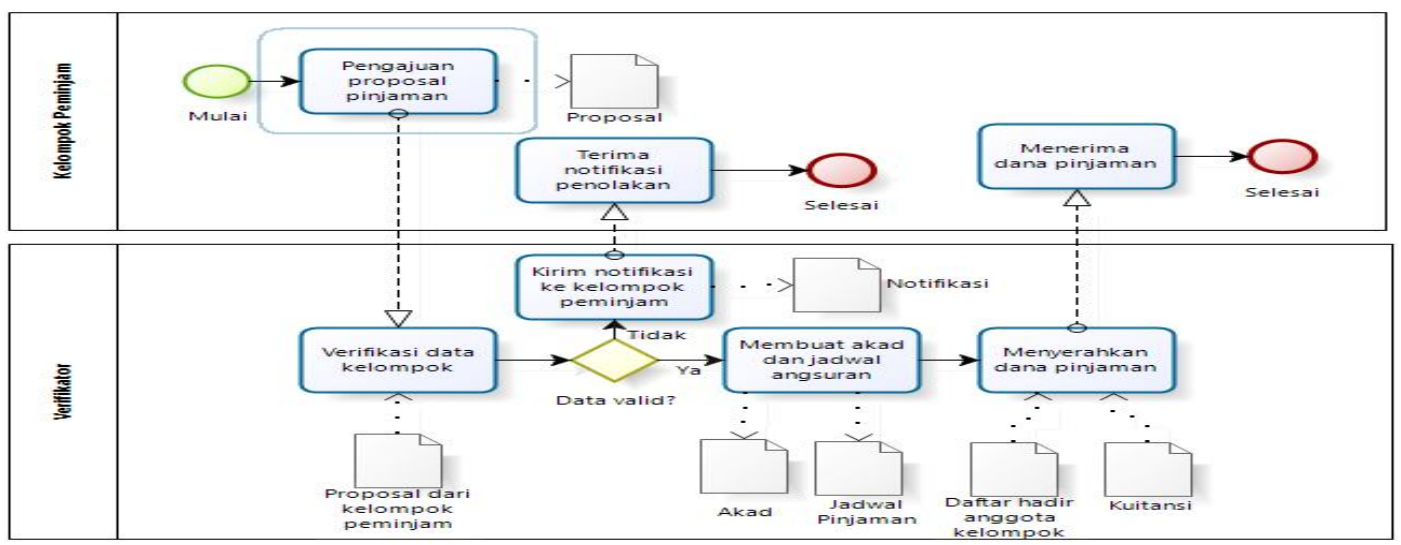

Gambar 8: Diagram proses bisnis perguliran pinjaman

Proses permohonan pinjaman hingga proses serah terima pinjaman dijelaskan melalui diagram proses bisnis seperti pada Gambar 8 . Kelompok peminjam mengajukan proposal pinjaman kepada UPK PNPM Mandiri kemudian staf verifikator melakukan verifikasi dan validasi data yang meliputi data anggota, data usaha per anggota, crosscek ke lapangan dan mengukur kemampuan tiap anggota dalam mengembalikan pinjaman. Jika permohonan ditolak maka verifikator akan mengirimkan notifikasi penolakan pinjaman kepada kelompok peminjam yang bersangkutan, disetujui maka akan segera dibuatkan akad pinjaman dan segera dialkukan proses serah terima dana pinjaman. Kedua belah pihak menandatangani akad pinjaman. Setiap anggota kelompok yang menerima pinjaman menadatangani kuitansi pencairan pinjaman dan menerima jadwal angsuran.

Pengembalian pinjaman merupakan proses anggota kelompok menyerahkan dana pinjaman kepada UPK PNPM Mandiri secara bertahap sesuai jadwal yang telah disepakati pada saat pencairan pinjaman. Gambaran proses pengembalian dapat dilihat pada gambar 9. Setiap proses pengembalian akan dilakukan verifikasi terhadap target pengembalian dan jasa pinjaman kepada peminjam sebagai salah satu cara untuk mengingatkan kekurangan angsuran atau keterlambatan. Aplikasi akuntansi berjalan pada sistem teknologi yang memanfaatkan koneksi jaringan lokal (Local Area Network) dan menggunakan model client-server. Model ini menempatkan data yang tersentralisasi pada satu sistem database pada server lokal.

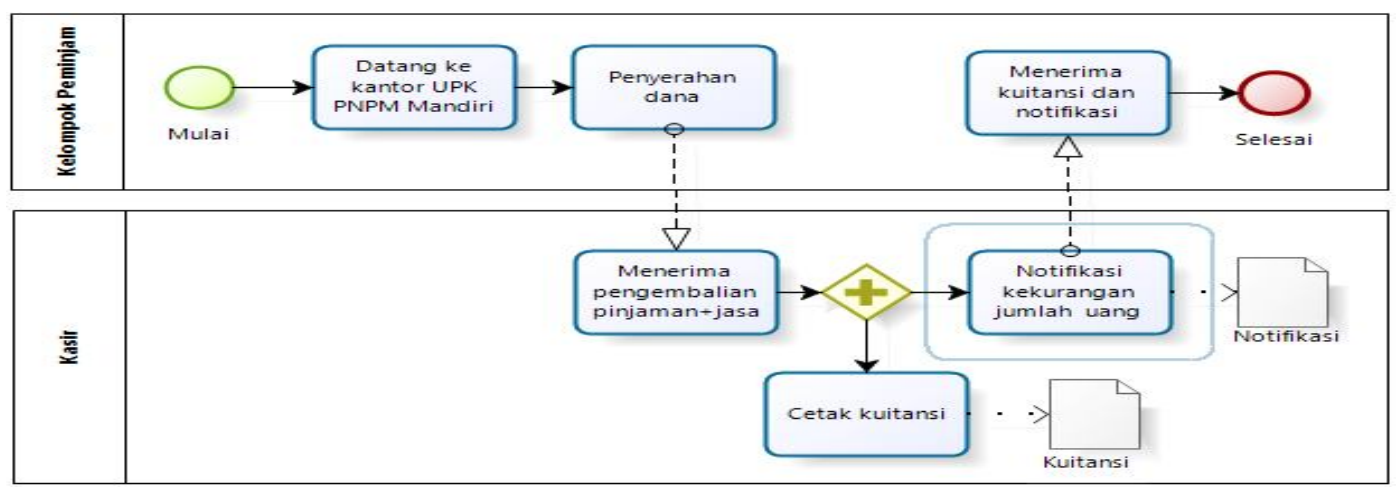

Gambar 9: Diagram proses pengembalian pinjaman 


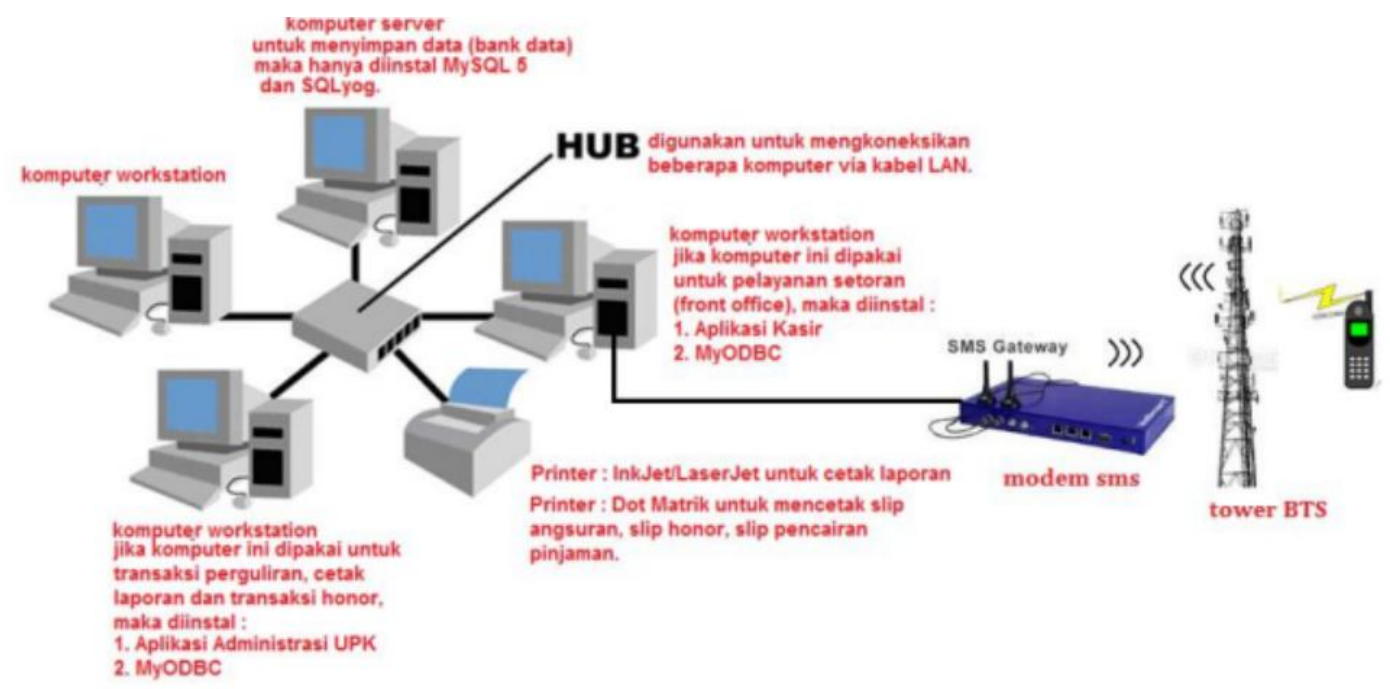

Gambar 10: Implementasi teknologi jaringan komputer lokal

Sistem yang berbasis web tidak digunakan pada pengelolaan data perguliran pinjaman UPK PNPM Mandiri karena segmen pengguna dari masyarakat adalah kelompok masyarakat bawah yang belum mengenal internet. Otorisasi data juga menjadi salah satu alasan mengapa jaringan lokal menjadi pertimbangan yang paling tepat. Selain itu masalah paling utama yang menghambat laju pekerjaan adalah proses rekapitulasi data transaksi untuk menjadi laporan keuangan periodik. Gambaran teknologi jaringan lokal dan data warehouse dapat dilihat pada gambar 10.

\section{KESIMPULAN}

Dari hasil pelaksanaan tentang
implementasi sistem informasi
akuntansi menggunakan metode
kustomisasi prototipe dan uji kesesuaian
menggunakan Zachman Framework,
dapat disimpulkan bahwa. Hasil
kustomisasi berhasil menyesuaikan
arsitektur proses bisnis dari level
konseptual hingga level fungsional.
Penggunaan aplikasi akuntansi
berdampak pada perspektif efisiensi

sumberdaya dan waktu dengan ditunjukkannya tertatanya database pada SIA terkait peminjaman bergulir. Implementasi sistem informasi akuntansi dapat digunakan sebagai pendukung dalam perubahan motivasi kerja terutama dalam pemrosesan data keuangan organisasi.

\section{UCAPAN TERIMA KASIH}

Kami mengucapkan terima kasih kepada UPK Kecamatan Dlingo dan UPK Kecamatan Pleret Bantul Yogyakarta. Lembaga Pendidikan, Penelitian, dan Pengabdian pada Masyarakat (LP3M) Universitas Muhammadiyah Yogyakarta atas kemitraan pelaksanaan program pengabdian masyarakat.

\section{DAFTAR PUSTAKA}


DIY, BPPM 2016, 'Peningkatan Kapasitas UPK PNPM Perdesaan', Pemprov DIY, Pemprov DIY, http://www.bppm.jogjaprov.go.i d, Yogyakarta.

Irastina, N 2013, 'Analisis Kinerja Keuangan Unit Pengelola Kegiatan PNPM Mandiri Perdesaan Kabupaten Purbalingga', eprints.ums, p. 3.

Isfahani 2015, 'Analisis Transformasi UPK PNPM Mandiri Perdesaan Menjadi Lembaga Keuangan Mikro', Thesis, no. Strategi Pengembangan UPK, pp. 37-39.

Jafar, M 2016, 'Mencari Pengelola Dana Rp12,7 Triliun', Kementerian Desa, Pembangunan Daerah Tertinggal, http://www.mediaindonesia.com /news/read/31430/mencaripengelola-dana-rp12-7triliun/2016-03-01\#, Jakarta.

Kementerian Desa, PDTDT 2015, , in UU Nomor 6 tahun 2014 tentang Desa, https://www.merdeka.com/perist iwa/jadi-pendamping-desa-eks- fasilitator-pnpm-harus-ikutaturan.html, Jakarta.

Kesra, DM 2008, Pedoman Pelaksanaan Sistem Pengelolaan Informasi PNPM Mandiri, Menko Kesra, Jakarta. Kurniawanto, RT 2014, 'Pengaruh Pinjaman Modal Kegiatan SPP PNPM mandiri Perdesaan Serta Sikap Wirausaha Terhadap Perkembangan Usaha dan Peningkatan Pendapatan Masyarakat Kec. Ambal Kab. Kebumen', eprints.uny, no. Wirausaha, pp. 69-70.

pnpm-mandiri.org 2011, 'Pilar II : Keberlanjutan Pendampingan', in Road Map PNPM Mandiri, Perpustakaan Digital Satker Pusat PNPM Mandiri, Jakarta.

Saktiyana, T 2010, '70\% APBD Bantul Dialokasikan Untuk Kesejahteraan Dan Pemberdayaan Masyarakat', Pemerintah Daerah Kabupaten Bantul, Dinas Perindagkop, https://bantulkab.go.id/berita/90 5.html, Yogyakarta. 